258 Meurer, Beantwortung d. gestellt. Frage "über Bleiglasur «:

glätte 3 Theile Lehm genommen und das Geschirr nicht bei zu geringem Feuer gebrannt wird. Ist das Feuer zu gering, so ist allerdings auch bei diesem Verhältniss von Blei und Zusatz möglich, eine schlechte Glasur zu erzeugen. Ebenso kann eine Glasur bei einem etwas grössern Zusatz von Blei, z. B. bei 1 Theil Lchm auf 2 Theile Glätte noch gut, d. h. ohne Blei an Essig abzugehen, hervorgebracht werden, wenn das Geschirr etwas stärker gebrannt wird.

Man sicht also hieraus, dass nicht allein vom richtigen Verhällnisse des Bleioxyds zum Lehm, sondern auch vom Feuersgrad etwas abhängt. Man darf aber wiederum nicht glauben, dadurch, dass man ein schärfercs Brennen fördere oder anordne, Alles zu erreichen, denn ein zu scharf gebranntes Geschirr ist, da es den Temperaturwechsel nicht gut verträgt, nicht für die Haushaltungen brauchbar.

Da also sowohl ein richtiges Verhältniss der Bleiglätte und des Zusatzes, als auch ein bestimmter, mittlerer Feuersgrad dazu gehört, um ein ganz unschädiiches und brauchbares Geschirr mit Blciglasur zu crhalten, und da besonders der Fouersgrad nicht genau, d. h. nach Maass oder Gewicht den Töpfern angegeben werden kann, so ist es immer zu wünschen, dass eine allgemein anwendbare, wohlfeile Glasur, anstatt der wohl zu erlangenden, aber nicht genau anzugebenden Ait, cine gute Bleiglasur zu erzeugen, gefunden werde. Den Wunsch, dass es einer Regierung oder einem Vereine gefallen möchte, eine Preisfrage, wie eine bleifreie Glasur wohlfeil und allerwärts zu erzeugen sei, stellen möchte, habe ich schon bei Mitthcilung meiner oben erwähnten Abhandlung ausgesprochen.

\title{
Ueber eine Kohle aus dem unteren Wellenkalke bei Jena; \\ von
}

Dr. Ernst Schmid, Professor zu Jena.

Die Kohle, deren Untersuchung hier gegeben werden soll, zerfallt in unregelmässig parallelepipedische Stücke, die 
jedoch keine Spur eines ihrer Oberfläche entsprechenden Blätterdurchganges zeigen. Die parallelepipedische Zertheilung ist uberhaupt durchaus nicht auf krystallinische Formen $\mathrm{zu}$ beziehen, sondern wird dadurch bedingt, dass grössere Kohlenparthien netzförmig von dünnen Mergelblättchen durchzogen sind.

Die Kohle ist also derb; sie hat einen ausgezeichnet kleinmuschligen Bruch, ist im geringen Grade milde und leicht zerreiblich, ihre Härte ist $=2,5$, d. h. Gyps wird von ihr geritzt, von Kalkspath wird sie geritzt; ihr specifisches Gewicht beträgt 1,4; sie ist pechschwarz, im Striche bräunlichschwarz, auf frischen Bruchflächen glasartig fettglänzend, sonst fettglänzend bis matt, undurchsichtig.

Sie kommt in handgrossen Stücken von höchstens $\frac{1}{2}$ Zoll Dicke zwischen den Mergelschichten des unteren Wellenkalks vor und ist bis jetzt nur am sudlichen Abhange des Jenzigs bei Wogau, einem I Stunde von Jena an der Chaussee nach Eisenberg gelegenen Dorfe, zugleich mit Cölestin gefunden worden.

Im Kolben erhitzt, giebt diese Kohle zuerst Wasser aus, später stark ammoniakalische Dämpfe, zuletzt weisse Nebel, aus denen sich ein in Aether lösliches, blassgelbes Brandharz in sehr geringer Menge abscheidet; der Rückstand der Kohle nach dem Glühen ist eisenschwarz und hat einen höheren demantartigen Glanz angenommen.

Auf Platinblech über der Spirituslampe erhitzt, glimmt die Kohle kaum; in der Oxydationsllamme des Löthrohrs verbrennt sie langsam, indem sie sich mit einer weissen Asche uiberzieht.

In Wasser zerspringen grössere Stücken mit einem deutlich knisternden Geräusch. Nach längerer Digestion färbt sich das Wasser schwach gelblich und hat etwas Humussäure aufgenommen.

Aether zieht eine Spur von hellgelbem Harz aus.

Die Alkalien und kohlensauren Alkalien lösen einen Theil der Kohle mit brauner Farbe auf. Aus der Auflösung scheiden sich auf Zusatz von Schwefelsäure oder 
Chlorwasserstoffsäure braune Flocken von Humussäure ab. während die Flüssigkeit wieder völlig farblos wird. Der ungelöste Theil bildet zuerst trapezoidische Stücke, die nach Monate langer Digestion stark aufschwellen und ein feinfaseriges Gefüge annehmen. Während der Digestion mit Kali findet bei niederer Temperatur eine kaum nachweisbare Entwickelung von Ammoniak statt. Denn nimmt man die Digestion in einer enghalsigen Flasche vor, deren Oeffnung mit einem angenässten Curcumapapier bedeckt ist. so lässt sich auch nach längerer Zeit keine Bräunung des letztern erkennen; dagegen entstehen schwache weisse $\mathrm{Ne}$ bel, wenn man einen mit Chlorwasserstoffsäure oder Essigsäure benetzten Glasstab in den Hals hineinhält, nachdem die Flasche einige Zeit verschlossen war. Lässt man bei der Digestion eine bis zum Sieden gesteigerte Temperatur eintreten, so entwickelt sich Ammoniak in reichlicher Menge.

Bei der Temperatur des siedenden Wassers verlor die Kohle einmal 19,8 Proc. von ihrem Gewichte, ein anderes Mal 20,1 Proc. Diese Cileichheit des Wassergehaltes verschiedener Kohlensticke, die iberdiess ungleich lange an der Luft gelegen hatten, deutet darauf hin, dass das Wasser nicht hygroskopisches, sondern hydratisches sei.

Nach wiederholter drei Monate lang fortgesetzter Digestion der Kohle mit Kalilösung betrug der gnt ausgewaschene und bei $80^{\circ}$ R. getrocknete Riickstand 46,1 Proc. Nach Abzug des Wassergehaltes blieben demnach für die gelöste Humussäure 34,1 Proc.; diese Angabe ist aber jedenfalls etwas zu niedrig, denn frische Kalilösung, auf den Rückstand gegossen, fürbte sich noch stark gelb.

Zur Bestimmung des Aschengehaltes wurde die Kohle mit salpetersaurem Ammoniak gemengt und das Gemenge portionenweise in einen geräumigen crhitzten Tiegel eingetragen, so dass durch die Verpuffung kein Verlust entstehen konnte. Die zurückbleibende Asche betrug 11,04 Proc. und bestand zum grössten Theil aus kohlensaurer Kalkerde mit etwas kohlensaurer Talkerde und schwefelsaurer Kalkerde, und wenig Eisenoxyd und Thonerde. Dass die zu diesem Versuche verwendete Kohle von ein- 
gemengten Mergelblättchen vollkommen gereinigt war, braucht wohl kaum erwähnt zu werden.

Bei mikroskopischer Untersuchung erschien die frische Kohle als eine dichte Masse ohne alle Spur von innerer Structur; je länger aber die Digestion mit Kali oder kohlensaurem Natron fortgesetzt war, desto deutlicher erkannte man ihre Zusammensetzung aus Holzzellen; im aufgeschwollenen und faserigen Zustande stellten sich die einzelnen Stücke als Massen vollkommen scharf bezeichneter, parallel neben einander liegender Zellen dar, an denen Hr. Prof. Schleiden die charakteristischen Merkmale der Coniferen erkannte. Diess ist nun keineswegs auffällig, denn man hat fossile Coniferen schon anderweitig im Gebiete des Muschelkalks gefunden. Neu und unerwartet ist dagegen die Auffindung von Laubholzblatlfragmenten mit erhaltenen Spiralgefässen und deutlicher Behaarung.

Die neu gefundene Muschelkalkkohle steht dem Obigen zufolge der Braunkohle sehr nahe, die ebenfalls viel Humussäure enthält und aus fossilen Coniferen besteht. Auch bei der Braunkohle tritt die organische Textur nach Digestion mit Kali oder kohlensaurem Natron, d. h. nach Entfernung der Humussäure, deutlicher hervor; dagegen entwickelt sie bei Behandlung mit Kali schon in der Kälte viel Ammoniak. Hinsichtlich des äussern Aussehens würde man unsere Wogauer Kohle der Pechkohle zur Seite stellen.

\section{Schwefel in Braunkohlen; von F. Rosenthal.}

Wenn auch Becks (Schweigg. Journ. N. R. B. 19. H. 3.) auf den Schwefelgehalt des Quarzsandes der Braunkohlenformation bei Bonn aufmerksam gemacht hat, und das Braunkohlenlager bei Artern als ein Fundort des gediegenen Schwefels genannt wird, so erlaube ich mir doch, von 